\title{
The frustration with utilization: why have improvements in internal phosphorus utilization efficiency in crops remained so elusive?
}

\author{
Terry J. Rose ${ }^{1+}$, Michael T. Rose ${ }^{1}$, Juan Pariasca-Tanaka' ${ }^{1}$, Sigrid Heuer ${ }^{2}$ and Matthias Wissuwa ${ }^{1}$ * \\ ${ }^{1}$ Crop Production and Environment Division, Japan International Research Center for Agricultural Sciences, Tsukuba, Japan \\ ${ }^{2}$ International Rice Research Institute, Los Banos, Philippines
}

\section{Edited by:}

Richard William Bell, Murdoch

University, Australia

Reviewed by:

Richard William Bell, Murdoch

University, Australia

Jianbo Shen, China Agricultural

University, China

Manny Delhaize, CSIRO Plant

Industry, Australia

*Correspondence:

Matthias Wissuwa, Crop Production and Environment Division, Japan

International Research Center for

Agricultural Sciences (JIRCAS),

1-1 Ohwashi, Tsukuba, Ibaraki

305-8686, Japan.

e-mail:wissuwa@affrc.go.jp

${ }^{+}$Present address:

Terry J. Rose, Southern Cross Plant Science, PO Box 157 Lismore NSW 2480, Australia.
Despite the attention internal phosphorus utilization efficiency (PUE) of crops has received in the literature, little progress in breeding crop cultivars with high PUE has been made. Surprisingly few studies have specifically investigated PUE; instead, genotypic variation for PUE has been investigated in studies that concurrently assess phosphorus acquisition efficiency (PAE). We hypothesized that genotypic differences in PAE confound PUE rankings because genotypes with higher PAE suffer a lower degree of $P$ stress, resulting in lower PUE. The hypothesis was tested by comparing soil-based screening to a modified technique whereby rice genotypes were grown in individual containers with a single dose of solution $\mathrm{P}$, to eliminate differences in $\mathrm{P}$ uptake among genotypes. Genotypic differences in PUE were apparent in root and shoot tissue using the modified nutrient solution technique, but PUE rankings showed no correlation with those from traditional soil-based screening. We conclude that PUE in soil-based screening systems is unavoidably linked with genotypic PAE, resulting in PUE rankings confounded by differences in P uptake. Only screening techniques assuring equal $P$ uptake are suitable for the exploitation of genotypic variation for PUE.

Keywords: internal use efficiency, phosphorus acquisition efficiency, root growth, screening method, phosphorus concentration

\section{INTERNAL PHOSPHORUS USE EFFICIENCY AS A KEY TRAIT}

The development of phosphorus (P) efficient crops that grow and yield well in soils low in plant-available $\mathrm{P}$ is a cost-effective means of improving crop yields in low-input farming systems (Ismail et al., 2007; Wissuwa et al., 2009). Such P-efficient crops would ideally combine high P uptake (phosphorus acquisition efficiency, PAE) with very efficient use of $P$ in biomass accumulation (phosphorus utilization efficiency, PUE). In this perspective piece PUE is defined as the amount of biomass produced per unit $\mathrm{P}$, which, in effect, is the inverse of tissue $\mathrm{P}$ concentration. Plants producing equal biomass at lower $\mathrm{P}$ concentrations (compared to other plants) or higher biomass at equal $\mathrm{P}$ concentrations would be considered to have high PUE.

While the importance of both aspects of P efficiency has long been recognized, efforts to identify genotypic differences and subsequently characterize underlying mechanisms and genes have disproportionally focused on PAE (Wang et al., 2010). In fact, when genotypic PUE has been assessed it has frequently been a minor objective of a study primarily designed to investigate PAE. In rice alone several such studies have reported genotypic differences in PAE while concurrently assessing PUE (Fageria et al., 1988; Hedley et al., 1994; Fageria and Baligar, 1997; Saleque et al., 1998; Wissuwa and Ae, 2001). Several similar studies have reported genotypic differences in PUE and PAE across multiple crop species (see recent reviews by Shenoy and Kalagudi, 2005; Wang et al., 2010).
In addition, a limited number of studies have reported Quantitative Trait Loci (QTL) for PUE (Wissuwa et al., 1998; Su et al., 2006; Chen et al., 2009).

However, despite the presence of genotypic variation for PUE and associated QTLs, there has been little progress in breeding crops with high PUE. The perspective presented here is that this lack of progress is in large part due to the fact that unsuitable methods have been employed in evaluating PUE. To overcome this limitation, we propose an alternative screening method that avoids pitfalls of PUE screening in soil and we provide first estimates of the genotypic variability for PUE present in rice.

\section{ESTIMATES OF PUE ARE TYPICALLY CONFOUNDED IF GENOTYPES DIFFER IN PAE}

It has long been recognized that as the $\mathrm{P}$ level in growing media increases, so do tissue $\mathrm{P}$ concentrations of plants grown in that media, effectively leading to lower PUE (Chisholm and Blair, 1988; Fageria et al., 1988; Saleque et al., 1998; Osborne and Rengel, 2002). The first evidence that this phenomenon confounds PUE in genotypic screening studies was provided by Wissuwa et al. (1998) who identified a major QTL for P uptake (Pup1) in rice. Surprisingly, the main QTL for PUE was mapped at the exact same location as P uptake, but whereas the $P u p 1$ locus almost doubled P uptake, it significantly reduced PUE, such that lines with the highest $\mathrm{P}$ uptake showed the lowest PUE. While it is possible that this negative 
association arises because a high PAE trait negates the need for these genotypes to evolve with high PUE traits, it seems equally likely that genotypes acquiring more $\mathrm{P}$ from soil in screening studies suffer a lower degree of P deficiency stress, and consequently, have lower PUE. Stated simply, the more P plants accumulate, the lower the PUE becomes and under realistic (field or soil-based) growing conditions, PUE and PAE are unavoidably linked.

To test this hypothesis a study was conducted comparing a traditional soil-based screening method with a modified, yet simple screening method where 29 genotypes were grown separately in containers in nutrient solution with a fixed amount of soluble $\mathrm{P}$ supplied. When plants were grown in $\mathrm{P}$ deficient Andisol soil (see Wissuwa and Ae, 2001 for details), genotypic variation was observed for total plant $\mathrm{P}$ uptake $\left(0.14-0.59 \mathrm{mg} \mathrm{plant}^{-1}\right)$ and for shoot PUE (shPUE) (1.45-3.61 g shoot dry weight $\mathrm{mg}^{-1} \mathrm{P}$; Figure 1). This has also been observed in similar studies with rice (Fageria et al., 1988; Hedley et al., 1994; Fageria and Baligar, 1997; Saleque et al., 1998; Wissuwa and Ae, 2001). As hypothesized, there was a significant negative correlation between shoot $\mathrm{P}$ accumulation (PAE) and shPUE $\left(R^{2}=0.70\right)$, clearly indicating that PUE and PAE are unavoidably linked in traditional screening studies, leading to confounded results.

\section{TRUE DIFFERENCES IN PUE ARE REVEALED IF ALL GENOTYPES HAVE THE SAME P SUPPLY}

To test our hypothesis that variation for PUE can only be assessed properly in the absence of differences in $\mathrm{P}$ accumulation, we developed a simple screening method where genotypes were grown individually in $140 \mathrm{~mL}$ plastic containers filled with Yoshida nutrient solution (Yoshida et al., 1976) with a fixed amount of P (500 $\mu \mathrm{g}$ $\mathrm{P}$ as $\left.\mathrm{Na}_{2} \mathrm{HPO}_{4}\right)$. Solution $\mathrm{P}$ concentrations in the $500-\mu \mathrm{g} \mathrm{P}$ bottles

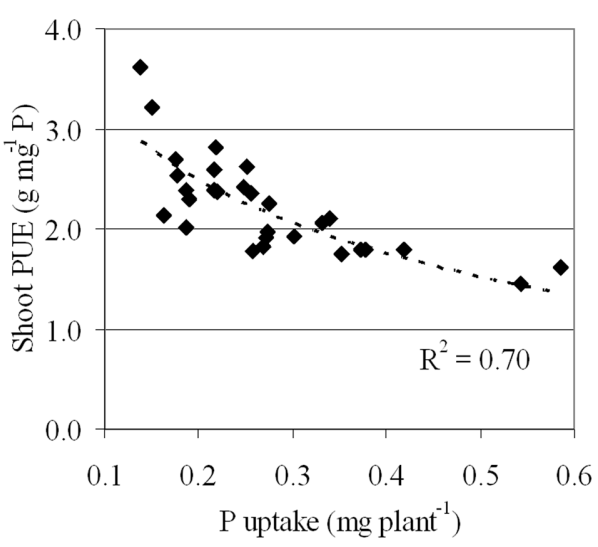

FIGURE 1 | Association between PUE and P accumulation across 29 rice genotypes that were grown in a greenhouse for $\mathbf{5 0}$ days in large $\mathbf{1} \mathbf{m} \times \mathbf{0 . 8} \mathbf{m} \times \mathbf{0 . 3} \mathbf{m}$ high free draining tubs filled with $P$ deficient Andisol. Germinated seeds were sown in a six row $\times$ five column grid per tub in a RCB design with four replicates. Plants received nitrogen $(N)$ fertilizer $14 \mathrm{DAS}$ at $2.5 \mathrm{~g} \mathrm{~N}$ per box as ammonium sulfate. Plants were watered weekly for the first 2 weeks then every 3 day for the duration of the experiment, with sufficient water added to allow some drainage from the bottom of the tubs. At harvest, root, and shoot material were separated and oven-dried at $60^{\circ} \mathrm{C}$ for $72 \mathrm{~h}$ and ground. A 0.5-g subsample was acid digested and $\mathrm{P}$ in the samples measured spectrophotometrically (Rose et al., 2010). dropped from around $20 \mu \mathrm{M} \mathrm{P}$ at day zero to less than $0.3 \mu \mathrm{MP}$ at day six, suggesting that all $\mathrm{P}$ was absorbed (for more details see Figure 2). This $500 \mu \mathrm{g} P$ treatment was compared with a control treatment with high $\mathrm{P}$ supply $(100 \mu \mathrm{M}$, supplied weekly) and to the soil screening described previously.

Plants in the 500- $\mu \mathrm{g} \mathrm{P}$ treatment responded similarly to those in the soil-based treatment in that plants began showing symptoms of P deficiency (yellowing of older leaves) beyond 30 DAS. At 50 DAS P deficiency was reflected in average shoot $\mathrm{P}$ concentrations of 0.49 and $0.74 \mathrm{mg} \mathrm{g}^{-1}$ for plants grown in soil or in hydroponics with $500 \mu \mathrm{g}$ P, respectively, which were well below the critical value of $1 \mathrm{mg} \mathrm{g}^{-1}$ for vegetative stage plants (Dobermann and Fairhurst, 2000). Growing plants for a 6-week period ensured that all plants became $\mathrm{P}$ deficient, such that differences in seedling vigor did not confound the results; rather, genotypes with higher initial growth rates simply became $\mathrm{P}$ deficient earlier. Further, plant biomass was three times higher and $\mathrm{P}$ uptake ten times higher in the plus-P control than in the 500- $\mu$ g P treatment (data not shown), indicating that under sufficient $\mathrm{P}$ supply plant growth was not inhibited by the growth conditions (i.e., $140 \mathrm{~mL}$ bottles supplied with nutrient solution).

Genotypic variation in shPUE ranged from 1.08 to $1.58 \mathrm{~g}$ dry weight $\mathrm{mg}^{-1} \mathrm{P}$ in the $500-\mu \mathrm{g} \mathrm{P}$ treatment (Figure 2A), confirming that genotypic variation for PUE does exist in the absence of confounding effects of differential $\mathrm{P}$ accumulation. In roots the overall PUE was higher (1.63 to $2.61 \mathrm{~g} \mathrm{mg}^{-1} \mathrm{P}$; Figure $2 \mathrm{~B}$ ), as also observed by Fageria et al. (1988), suggesting that at least in rice, roots have a lower $\mathrm{P}$ cost than shoots. Further examination of the relatedness between different traits suggest that the genotypic differences observed in the 500- $\mu \mathrm{g} \mathrm{P}$ treatment are indeed valid estimates of genotypic variation for PUE. Correlation coefficients between shPUE and total P accumulation (TP) showed a negative association in all three screening treatments (Table 1), which is to be expected because shPUE, the inverse of shoot $\mathrm{P}$ concentration, will always be correlated to shoot $\mathrm{P}$ accumulation which is defined as biomass $\times \mathrm{P}$ concentration. However, the tight correlation $(r=-0.81)$ in the soil treatment indicates that $\mathrm{P}$ accumulation has an overriding bearing on shPUE and that high PUE (low shoot $\mathrm{P}$ concentration) was most likely the result of $\mathrm{P}$ starvation due to insufficient $\mathrm{P}$ uptake.

The relationships between shPUE and plant biomass are even more telling: shPUE should be positively related to biomass production if it is truly defined as "efficiency." However, such was only the case in the 500- $\mu \mathrm{g}$ P treatment ( $r=0.51$; Table 1$)$. That shPUE was negatively correlated to biomass production in the soil experiment $(r=-0.65)$ is consistent with our hypothesis that $\mathrm{P}$ uptake drives growth in such systems and confounds PUE rankings. This notion was further confirmed by partial correlations: when adjusted for TP, the residual correlation between TDWt and ShPUE changed from the original negative 0.65 in the low-P soil to a positive 0.76 (Table 1 ). The respective change in the plus- $P$ treatment was also very significant (from -0.02 to 0.94 ) but only gradual in the $500-\mu \mathrm{g} P$ treatment (from 0.51 to 0.88 ), indicating that screening experiments that allow genotypes to differ in $\mathrm{P}$ uptake will lead to PUE estimates that are strongly affected by plant $\mathrm{P}$ content. Interestingly, the lack of any significant relationship between shPUE and biomass in the plus-P treatment suggests biomass was driven (or limited) by factors other than P nutrition. 

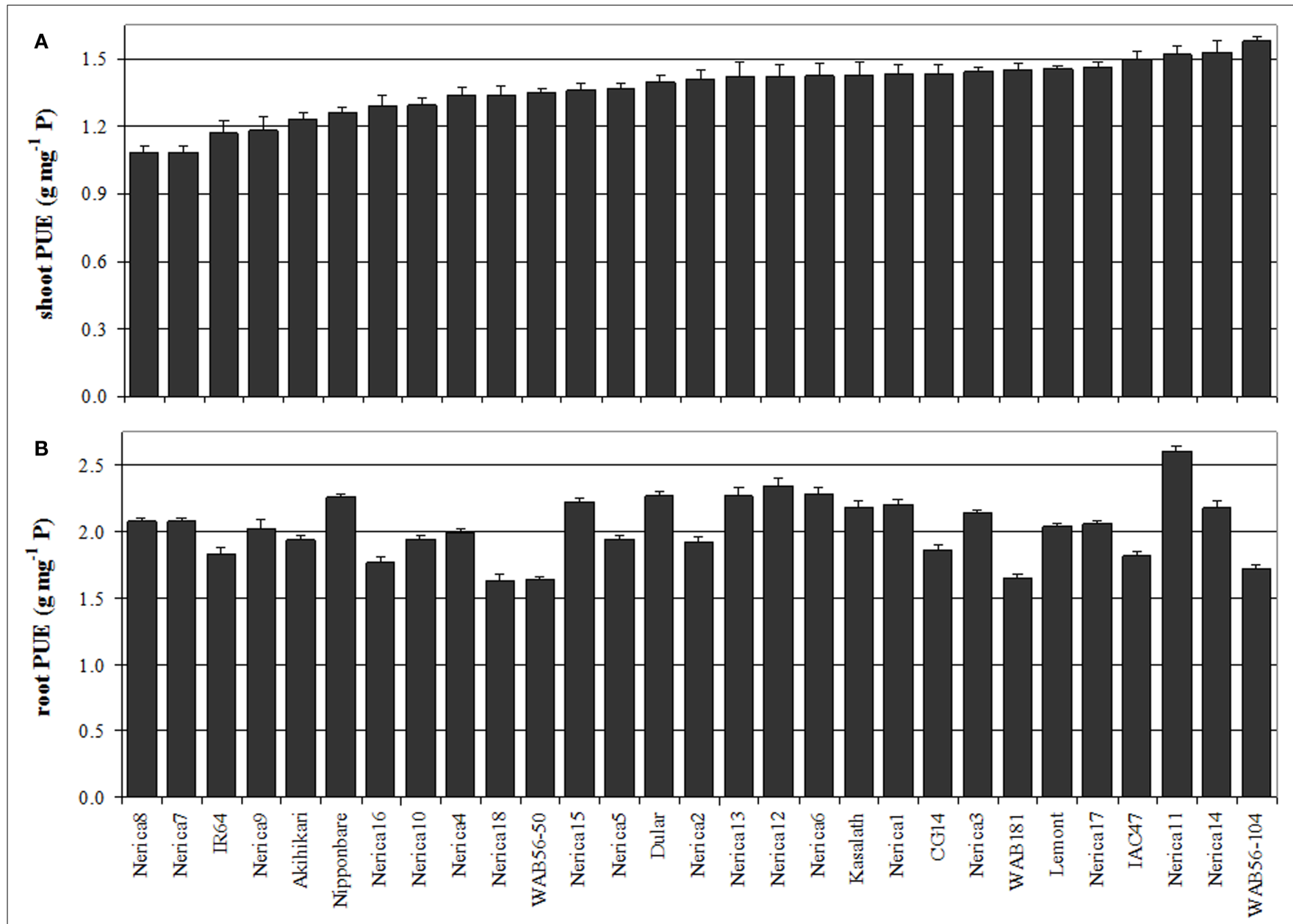

FIGURE 2 | Variation in shoot (A) and root (B) PUE among 29 rice genotypes grown in individual bottles supplemented with $500 \mu \mathrm{g}$ soluble P. Seedlings were raised on a floating mesh and after 13 days were transferred in pairs to $140 \mathrm{~mL}$ bottles (plants were supported by foam material) filled with full strength Yoshida solution and a one-time shot of
$500 \mu \mathrm{g} P$ per bottle as $\mathrm{Na}_{2} \mathrm{HPO}_{4-}$. The $\mathrm{pH}$ was adjusted to 6.5 and buffered using $1 \mathrm{mM}$ MES. Bottles were re-filled with DI water twice per week for the first 2 weeks, every second day for the ensuing 2 weeks then daily for the duration of the experiment. Each week, $10 \mathrm{~mL}$ nutrient solution $(5 \times$ Yoshida - without $\mathrm{P}$ for the $500-\mu \mathrm{g} P$ treatment) was pipetted into each bottle.
Thus, while genotypic differences existed in all three screening systems investigated, only those in the 500- $\mu$ g $\mathrm{P}$ treatment can be considered valid under the definition of "efficiency" and warrant further examination. The positive relationship between PUE and biomass in the 500- $\mu \mathrm{g} \mathrm{P}$ treatment ensures that the modified screening method does not select for low growth rates.

The modified method presented here could be used to screen large numbers of rice genotypes for PUE for purposes such as QTL or association mapping with some adaptations. One necessary adjustment to the method would be to provide a larger dose of P than $500 \mu \mathrm{g}$ P to nullify any effects of seed P content on PUE. In the present study, seed $\mathrm{P}$ content was associated with total plant $\mathrm{P}$ (Table 1), in effect conflicting with our goal of providing equal $\mathrm{P}$ to all genotypes. Increasing the amount of $\mathrm{P}$ supplied would render genotypic differences in seed $\mathrm{P}$ content negligible which should ultimately make it possible to simply use plant biomass to estimate PUE instead of relying on the more laborious tissue $\mathrm{P}$ concentrations. Further, while the level of $\mathrm{P}$ stress imposed by providing $500 \mu \mathrm{g} P$ created plants of similar size to those in the soil treatment, such $\mathrm{P}$ deficient plants are not representative of fieldgrown plants: increasing the amount of $\mathrm{P}$ supplied would enable screening at more realistic levels of $\mathrm{P}$ stress.

It is further acknowledged that differences in partitioning of $\mathrm{P}$ between roots and shoots of individual genotypes may influence the root or shPUE of that genotype, and that this relationship may further be affected by feedback mechanisms that exist when roots are grown in soil. However, in the absence of a better screening system, we propose that the screening method developed in this study provides the best chance known to separate the impacts of PUE and PAE and to allow identification of QTL that confer higher PUE in future studies.

\section{ARE GENOTYPIC DIFFERENCES FOR PUE LARGE ENOUGH TO JUSTIFY BREEDING?}

Genotypic variation for PUE was observed in shoots and roots but genotypic ranking differed entirely between the PUEs in both 
Table 1 | Correlation coefficients between biomass and P accumulation and utilization* parameters for 29 rice genotypes after a 50-day growth period in low-P soil compared to growth in individual containers filled with nutrient solution and either a one-time dose of $500 \mu \mathrm{g} P$ or continuous high P supply.

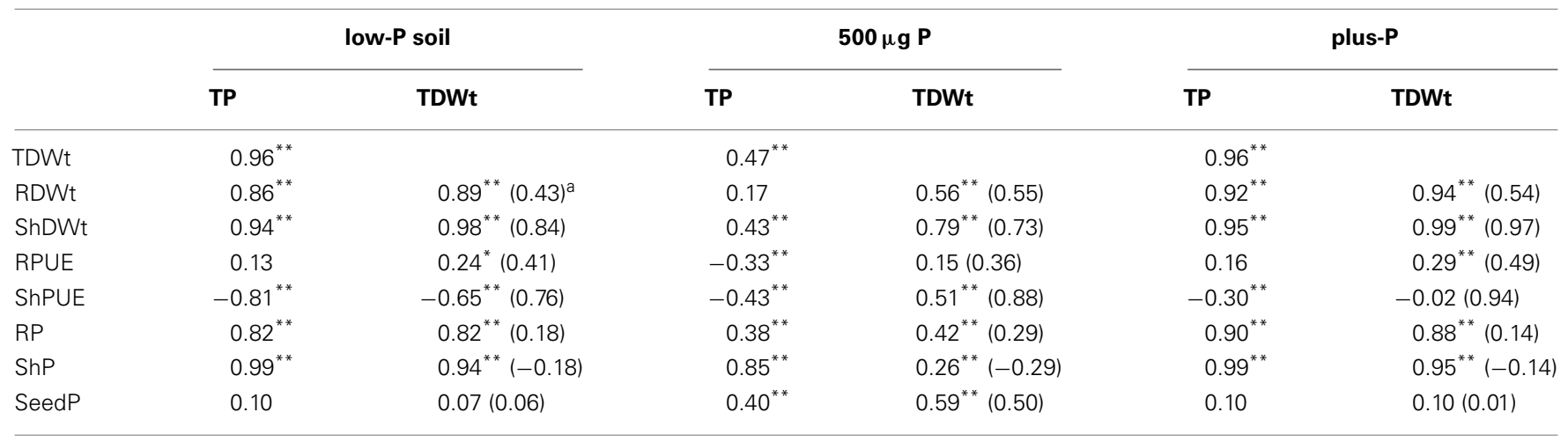

TDWt, total dry weight; RDWt, root dry weight; ShDWt, shoot dry weight; RPUE, root phosphorus use efficiency; ShPUE, shoot phosphorus use efficiency; RP, root total phosphorus; ShP, shoot total phosphorus; SeedP, seed total phosphorus.

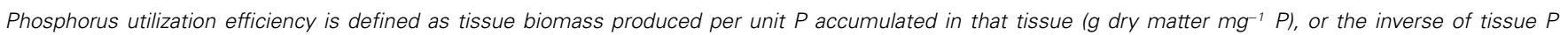
concentration (mg P $g^{-1}$ dry matter). ${ }^{*}$ and ${ }^{* *}$ indicate significance at $p=0.05$ and $p=0.01$, respectively $(n=116)$.

${ }^{a}$ Values in brackets are residual correlations to TDWt based on a partial correlation analysis where correlations with TDWt have been adjusted for the factor TP.

tissues (Figure 2), indicating that root and shPUE are independent traits and that they may be selected for separately in a breeding program. In this nutrient solution experiment, the overriding contribution of shoot dry weight to total dry weight and the significant correlation between total dry weight and shPUE $(r=0.51$; Table 1), but not with root PUE, suggest that shPUE may be a more critical factor when looking to improve PUE in crops. However, when plants are grown in soil the importance of root PUE is expected to increase as outlined further below.

In breeding, the maximum difference detectable within germplasm is of less relevance than the difference between average and maximum expression of a trait. Using the five most efficient genotypes in comparison to the average gives a rough estimate for the achievable selection differential of about 14 and 20\% higher PUE for shoots and roots, respectively. Such relatively low variability raises the question as to whether breeding for PUE would improve performance in low-P fields. This question is difficult to assess experimentally unless it can be ruled out that the genotypes evaluated differ in PAE. However, theoretically this question can be addressed using the plant growth model "P-LIM-GROW" that had been developed to simulate plant growth and $\mathrm{P}$ uptake under severely P deficient conditions (Wissuwa, 2003). Briefly, the model assumes that root growth is directly limited by $\mathrm{P}$ rather than by assimilate availability. This assumption has been confirmed by the finding that excess assimilates accumulate in form of starch in roots of $\mathrm{P}$ deficient plants and more so in plants suffering a higher level of P deficiency (Wissuwa et al., 2005). Root biomass accumulation would thus depend on the amount of $\mathrm{P}$ distributed to root tissue and on root PUE. Root architectural parameters and PAE will subsequently determine how much $\mathrm{P}$ is taken up by the root biomass. This quantity of $\mathrm{P}$ is distributed between shoots and roots, initiating another cycle of biomass accumulation.

At any time " $x$ " a genotype with a 20\% higher root PUE would accumulate $20 \%$ more root biomass, leading to increased soil exploration and up to $20 \%$ higher P uptake compared to a less efficient genotype. Assuming 30\% of $\mathrm{P}$ taken up remains in roots, the additional benefit to the high PUE genotype in $t=\mathrm{x}+1$ would be a $6 \%$ increase in $\mathrm{P}$ distribution to roots that would also be turned into root biomass with the $20 \%$ higher efficiency, resulting in an extra $27.2 \%$ root biomass and $\mathrm{P}$ uptake in $t=\mathrm{x}+1$. Model simulations with P-LIM-GROW, using parameter functions derived from experimental data of $\mathrm{P}$ deficient Nipponbare, predicted that a $10 \%$ increase in root PUE would increase $\mathrm{P}$ uptake over a 98 -day growth period by $53-78 \%$ and a $20 \%$ increase would increase P uptake by almost 200\% (Wissuwa, 2003). These values represent upper limits since overlapping depletion zones in more mature root systems were not taken into account in the model.

These simulations suggest that a relatively small increase in root PUE would substantially improve P efficiency over an entire growth period because subsequent root growth and $\mathrm{P}$ uptake effects would amplify the initial effect of higher PUE. Improving PUE in crops through breeding would, therefore, lead to results similar to those expected for improving PAE; that is, ultimately $\mathrm{P}$ acquisition will improve no matter which trait has been targeted in breeding. Similar conclusions were drawn by Postma and Lynch (2010) based on studies of aerenchyma formation in P deficient roots, which was seen as a way of enhancing the efficiency of root development with positive effects on $\mathrm{P}$ uptake. This example further provides evidence for different efficiency mechanism operating in roots versus shoots.

\section{CONCLUSION}

The results of the present study clearly show that genotypic comparisons of PUE are biased if genotypes differ in P uptake, and therefore, identification of high PUE genotypes and valid QTLs for high PUE traits requires screening methods that either separate the effects of PUE from $\mathrm{P}$ accumulation, or at least minimize differences in $\mathrm{P}$ uptake between genotypes. It is perhaps for this reason that, despite the large number of studies reporting genotypic differences for PUE and even mapping of the associated 
QTLs, no practical breeding outcomes have been achieved and no mechanisms for high PUE in crop genotypes elucidated thus far. The modified method used in the present study avoided competition for $\mathrm{P}$ between individual genotypes to assure equal $\mathrm{P}$ supply translated to equal $\mathrm{P}$ uptake, and true genotypic variation for PUE was revealed. However, in future studies the duration of screening and the amount of $\mathrm{P}$ supplied should be dimensioned to nullify genotypic differences in seed $\mathrm{P}$ content or seedling vigor. Increased $\mathrm{P}$ supply to nullify seed $\mathrm{P}$ content will also allow screening of plants at low levels of $\mathrm{P}$ stress than those imposed in the present study. While labor intensive, the concept of screening large numbers of

\section{REFERENCES}

Chen, J., Xu, L., Cai, Y., and Xu, J. (2009). Identification of QTLs for phosphorus utilisation efficiency in maize (Zea mays L.) across P levels. Euphytica 167, 245-252.

Chisholm, R. H., and Blair, G. J. (1988). Phosphorus efficiency in pasture species. I. Measures based on total dry weight and $\mathrm{P}$ content. Aust. J. Agric. Res. 39, 807-816.

Dobermann, A., and Fairhurst, T. H. (2000). Nutrient Disorders and Nutrient Management. Singapore: Potash and Phosphate Institute, Potash and Phosphate Institute of Canada and International Rice Research Institute.

Fageria, N. K., and Baligar, V. C. (1997). Upland rice genotypes evaluation for phosphorus use efficiency. J. Plant Nutr. 20, 499-509.

Fageria, N. K., Wright, R. J., and Baligar, V. C. (1988). Rice cultivar evaluation for phosphorus use efficiency. Plant Soil 111, 105-109.

Hedley, M. J., Kirk, G. J. D., and Santos, M. B. (1994). Phosphorus efficiency and the forms of soil phosphorus used by upland rice cultivars. Plant Soil 158, 53-62.

Ismail, A. M., Heuer, S., Thomson, J. T., and Wissuwa, M. (2007). Genetic and genomic approaches to develop rice germplasm for problem soils. Plant Mol. Biol. 65, 547-570.

Osborne, L. D., and Rengel, Z. (2002). Genotypic differences in wheat for uptake and utilisation of $\mathrm{P}$ from iron phosphate. Aust. J. Agric. Res. 53, 837-844.

Postma, J. A., and Lynch, J. P. (2010). Theoretical evidence for the aerenchyma in soils with low phosphorus availability. Ann. Bot. 107, 829-841.

Rose, T. J., Pariasca-Tanaka, J., Rose, M. T., Fukuta, Y., and Wissuwa, M. (2010). Genotypic variation in grain phosphorus concentration; and opportunities to improve P-use efficiency in rice. Field Crops Res. 119, 154-160.

Saleque, M. A., Abedin, M. J., Panaullah, G. M., and Bhuiyan, N. I. (1998). Yield and phosphorus efficiency of some lowland rice varieties at different levels of soil-available phosphorus. Commun. Soil Sci. Plant Anal. 29, 2905-2916.

Shenoy, V. V., and Kalagudi, G. M. (2005). Enhancing plant phosphorus use efficiency for sustainable cropping. Biotechnol. Adv. 23, 501-513.

Su, J., Xiao, Y., Li, M., Liu, Q., Li, B., Tongg, Y., Jia, J. and Li, functional benefit of root cortical

genotypes equal plant $\mathrm{P}$ uptake would allow for the identification of genotypes with high PUE and, potentially, of loci associated with this superior PUE. Only once this has been achieved would it be possible to truly test which of the mechanisms suggested as improving PUE would be associated with genetic variability and, hence, with a potential to be exploited in crop breeding.

\section{ACKNOWLEDGMENTS}

Terry J. Rose and Michael T. Rose express their gratitude to Japan Society for the Promotion of Science (JSPS) for Postdoctoral Fellowships that enabled this work to be carried out.

Z. (2006). Mapping QTLs for phosphorus-deficiency tolerance at wheat seedling stage. Plant Soil 281, 25-36.

Wang, X., Shen, J., and Liao, H. (2010). Acquisition or utilisation, which is more critical for enhancing phosphorus efficiency in modern crops? Plant Sci. 179 , 302-306.

Wissuwa, M. (2003). How do plants achieve tolerance to phosphorus deficiency? Small causes with big effects. Plant Physiol. 133, 1947-1958.

Wissuwa, M., and Ae, N. (2001). Genotypic variation for tolerance to phosphorus deficiency in rice and the potential for its exploitation in rice improvement. Plant Breed. 120, 43-48.

Wissuwa, M., Gamat, G., and Ismail, A. (2005). Is root growth under phosphorus deficiency affected by source or sink limitations? J. Exp. Bot. 56, 1943-1950.

Wissuwa, M., Mazzola, M., and Picard, C. (2009). Novel approaches in plant breeding for rhizosphere-related traits. Plant Soil 321, 409-430.

Wissuwa, M., Yano, M., and Ae, N. (1998). Mapping of QTLs for phosphorus-deficiency tolerance in rice (Oryza sativa L.). Theor. Appl. Genet. 97, 777-783.
Yoshida, S. D., Forno, A., Cock, J. K. and Gomez, K. A. (1976). Laboratory Manual for Physiological Studies of Rice. Manila: International Rice Research Institute (IRRI).

Conflict of Interest Statement: The authors declare that the research was conducted in the absence of any commercial or financial relationships that could be construed as a potential conflict of interest.

Received: 13 July 2011; accepted: 16 October 2011; published online: 01 November 2011.

Citation: Rose TJ, Rose MT, PariascaTanaka J, Heuer $S$ and Wissuwa $M$ (2011) The frustration with utilization: why have improvements in internal phosphorus utilization efficiency in crops remained so elusive? Front. Plant Sci. 2:73. doi: 10.3389/fpls.2011.00073

This article was submitted to Frontiers in Plant Nutrition, a specialty of Frontiers in Plant Science.

Copyright (C) 2011 Rose, Rose, PariascaTanaka, Heuer and Wissuwa. This is an open-access article subject to a nonexclusive license between the authors and Frontiers Media SA, which permits use, distribution and reproduction in other forums, provided the original authors and source are credited and other Frontiers conditions are complied with. 